\title{
Article \\ Seed Treatment with $\alpha$-Tocopherol Regulates Growth and Key Physio-Biochemical Attributes in Carrot (Daucus carota L.) Plants under Water Limited Regimes
}

\author{
Abdul Hameed ${ }^{1}$, Nudrat Aisha Akram 1,*0, Muhammad Hamzah Saleem ${ }^{2}$, Muhammad Ashraf ${ }^{3}$, \\ Shakeel Ahmed ${ }^{4}$, Shafaqat Ali ${ }^{5,6, *}$, Abdulaziz Abdullah Alsahli ${ }^{7}$ and Mohammed Nasser Alyemeni ${ }^{7}$ \\ 1 Department of Botany, Government College University, Allama Iqbal Road, Faisalabad 38000, Pakistan; \\ hameedabdul743@gmail.com \\ 2 MOA Key Laboratory of Crop Ecophysiology and Farming System in the Middle Reaches of the Yangtze \\ River, College of Plant Science and Technology, Huazhong Agricultural University, Wuhan 430070, China; \\ saleemhamza312@webmail.hzau.edu.cn \\ 3 Department of Botany, University of Agriculture, Faisalabad 38040, Pakistan; ashrafbot@yahoo.com \\ 4 Instituto de Farmacia, Facultad de Ciencias, Universidad Austral de Chile, Valdivia 5110566, Chile; \\ shakeel1177@uach.cl \\ 5 Department of Environmental Sciences and Engineering, Government College University Allama Iqbal Road, \\ Faisalabad 38000, Pakistan \\ 6 Department of Biological Sciences and Technology, China Medical University, Taichung 40402, Taiwan \\ 7 Department of Botany and Microbiology, College of Science, King Saud University, \\ Riyadh 11451, Saudi Arabia; aalsahlaalshenaifi@ksu.edu.sa (A.A.A.); mnyemeni@ksu.edu.sa (M.N.A.)

Citation: Hameed, A.; Akram, N.A.; Saleem, M.H.; Ashraf, M.; Ahmed, S.; Ali, S.; Abdullah Alsahli, A.;

Alyemeni, M.N. Seed Treatment with $\alpha$-Tocopherol Regulates Growth and Key Physio-Biochemical Attributes in Carrot (Daucus carota L.) Plants under Water Limited Regimes. Agronomy 2021, 11, 469. https://doi.org/ 10.3390/agronomy11030469

Academic Editor: Najeeb Ullah

Received: 28 December 2020

Accepted: 10 February 2021

Published: 4 March 2021

Publisher's Note: MDPI stays neutral with regard to jurisdictional claims in published maps and institutional affiliations.

\begin{abstract}
The influence of seed priming with varying levels (50 and $100 \mathrm{mg} \mathrm{L}^{-1}$ ) of alpha-tocopherol (Toc) was investigated in carrot plants under water-deficit conditions. For this purpose, two cultivars of carrot, DC4 and DC90, were selected and subjected to well-watered (100\% field capacity (FC)) and water-deficit stress ( $50 \%$ FC). After 21 days of water-deficit conditions, a significant suppression was observed in shoot and root fresh and dry weights, their lengths, chlorophyll $a, b$ and total contents, and total soluble proteins (TSP). However, an up-regulatory effect of water stress was observed on the concentrations of glycinebetaine (GB), hydrogen peroxide $\left(\mathrm{H}_{2} \mathrm{O}_{2}\right)$, malondialdehyde (MDA), ascorbic acid (AsA), total phenolics as well as the activities of catalase (CAT) and peroxidase (POD) enzymes. Exogenous application of alpha-tocopherol was effective in reducing the accumulation of $\mathrm{H}_{2} \mathrm{O}_{2}$ and MDA contents and improving all growth attributes, contents of chlorophyll, proline, GB, AsA, total phenolics, TSP, and the activities of CAT and POD enzymes. Of both carrot cultivars, cv. DC4 had better performance in terms of growth attributes, whereas the response of the two cultivars was similar in all other attributes varying water regimes. Overall, it is suggested that seed priming with $100 \mathrm{mg} \mathrm{L}^{-1}$ Toc was effective in improving plant growth attributes, osmoprotectants and the oxidative defense system of carrot plants under water-deficit conditions.
\end{abstract}

Keywords: Daucus carota; $\alpha$-tocopherol; drought stress; reactive oxygen species; antioxidants

\section{Introduction}

Water deficit stress commonly known as drought is the most devastating abiotic stress which adversely affects morphological, biochemical, physiological, anatomical and molecular characteristics of plants [1]. Due to drought stress, a significant decrease in growth and yield production of many crops was noticed that is believed to be associated with reduced transpiration rate, chlorophyll pigments, photosynthetic rate, water potential, and gaseous exchange characteristics [2,3]. Morphological adaptations such as trichome/bark thickness and leaf wax can effectively suppress water loss, thereby providing protection to plants against water shortage conditions [4]. Water shortage affects the concentration 
and composition of plant primary as well as secondary metabolites [5]. Depending on cultivated practices and types of plant species, drought stress influences almost all the main classes of plant metabolites [6]. To adapt to arid environments, the plant expresses an extremely dynamic and complex process of homeostasis. Modulation of cell structure, hormone induction, scavenging of reactive oxygen species (ROS), kinase cascade signaling, osmolyte synthesis, regulation of gene expression, amino acid metabolism, nitrogen assimilation and ion channel activation are key mechanisms operating actively in response to drought stress $[7,8]$. Considerable variation in the functioning of a myriad of molecular, physiological and biochemical attributes was reported in the drought-stressed plants of different crops, e.g., mung bean [9], carrot [10], sunflower [11], and safflower [12]. Plants can also accumulate ROS under water-deficit regimes that may act as secondary messengers [13]. ROS of various forms like superoxide, hydroxyl radicals, hydrogen peroxide and singlet oxygen are generated in several parts of the cell such as microbodies, chloroplasts and mitochondria [14,15]. Another vital response of plants to drought stress is cell osmoregulation, which is mediated by the accumulation of solutes such as proline, sugars and glycinebetaine, and these biomolecules are believed to protect cellular structures and conserve cellular water content $[5,16]$. By accumulating osmoprotectant compounds such as proline, trehalose and polyamines, plants can resist a stress [17,18].

Alpha-tocopherol (Toc) is an effective oxygen-quenching micro-molecule, which accumulates to reasonable levels in plants. It is generally a lipophilic compound which is synthesized in the chloroplast, and most of the enzymes responsible for its biosynthesis are located on the inner membrane of the chloroplast envelope [9]. It is a major antioxidant that contributes in intracellular signaling, electron transport, photosystem-II, membrane stability and photo-protection. Tocopherols (alpha, beta and gamma) perform a role in a variety of diverse physiological phenomena including prevention of lipid peroxidation, delaying senescence and stimulation of signal cascade interactions that transfer biotic and abiotic signals [19]. Seeds and leaves contain varying concentrations of alpha-tocopherol. Under stress conditions, the concentrations of ROS in the biological membranes increase, which ultimately decreases $\alpha$-tocopherol contents [20]. Tocopherols are essential antioxidants that control ROS production. One molecule of tocopherol can effectively control 120 oxygen molecules [21]. Naturally, stress conditions regulate the synthesis of tocopherol [20]. It is the best active form of vitamin $\mathrm{E}$, which has considerable importance in humans' diet. It is mostly present in higher concentrations in vegetable oils (canola, almond and safflower), seeds, nuts or grains that are sources of high fats [22].

Exogenous application of antioxidants and vitamins on plants can minimize the negative effect of salinity and water stress on plant growth, yield quality and quantity [6]. Vitamins are considered as natural bioregulators, and various chemical activities may be affected even by their very small concentrations, but it depends on plant species or a stress, level of vitamin E, as well as different climatic conditions [23]. Alpha-tocopherol concentration changes due to associated genes expression and it is well known in that its high concentration in plants results in stress tolerance or resistance [21]. For example, seed treatment with alpha-tocopherol of wheat reduced oxidative stress and enhanced tolerance to temperature stress in the plants [24]. Moreover, adverse effects of ROS were reported to be nullified by the external supplementation of alpha-tocopherol [25], which could be ascribed to preservation of membrane stability and mitigation of lipid peroxidation [19].

Carrot (Daucus carota L.), a member of family Apiaceae, is an herbaceous biennial species. On the basis of pigments present in roots, cultivated carrots are generally classified into western and eastern carrots [10]. The storage root of carrot is a big source of dietary fibers, carotenoids, vitamins, antioxidants, carbohydrates, bioactive micronutrients and minerals (Fe, Ca, Mg and P) [26]. Due to a rich source of nutrients, it is good for human health [27]. Biotic and abiotic stresses greatly affect quality features of carrot [10]. It is a nitrophilous horticultural plant and has the capability to store a high amount of nitrate [27]. Keeping in mind the importance of Toc and carrot, the main objectives of the current 
study were to assess the influence of water deficit stress and pre-sowing treatment with $\alpha$-tocopherol on plant growth and physio-biochemical attributes of carrot plants.

\section{Materials and Methods}

\subsection{Experimental Design and Growth Conditions}

A greenhouse completely randomized design experiment was conducted to assess the role of pre-sowing seed treatment with alpha-tocopherol in improving growth and various physio-biochemical features of carrot plants subjected to water deficit conditions. During the experimentation, average temperature, $16.5-19.4{ }^{\circ} \mathrm{C}$, relative humidity, $75 \%$ and day length, $7.0 \mathrm{~h}$ were recorded. Seeds of two carrot cultivars (DC-4 and DC-90) were obtained from the Vegetable Section, Ayyub Agricultural Research Institute, Faisalabad, Pakistan. About 250 seeds of each carrot cultivar were sterilized, wrapped in a miracloth package followed by $5 \mathrm{~min}$ soaking in $0.5 \%$ sodium hypochlorite solution. Then, the seeds were rinsed briefly with deionized water and air-dried. For pre-sowing seed treatment, the seeds were soaked in three $\left(0,50\right.$ and $\left.100 \mathrm{mg} \mathrm{L}^{-1}\right)$ different concentrations of alpha-tocopherol along with $0.1 \%$ Tween- 20 as a surfactant for $14 \mathrm{~h}$. Sandy-loam soil (8 $\mathrm{kg}$ per pot) was obtained from the Ever-Green Nursery, Faisalabad, Pakistan. In each pot, 10 seeds were sown and allowed to germinate. After 10 days of seed germination, thinning was done and 5 plants were maintained in each plastic pot (diameter, $28 \mathrm{~cm}$ ). After one month of seed germination, the plants were subjected to drought stress at the rate of $50 \%$ field capacity (FC) in addition to control ( $100 \% \mathrm{FC})$. The drought stress was maintained by measuring the saturation percentage of the soil extract. Then, the pots were regularly monitored and we kept the weight of each pot equal to that calculated for $50 \%$ and $100 \%$ FC through addition of water. After 21 days of drought stress treatment, sampling was done to evaluate changes in the following morphological and physio-biochemical parameters in the carrot plants.

\subsection{Morphological Attributes}

Two carrot plants from each pot were uprooted carefully after watering the soil. Roots were washed carefully with distilled water and measured the root and shoot lengths using a scale $(\mathrm{cm})$. Root and shoot fresh weights were recorded by using an electrical weighing machine and placed in an oven at $65^{\circ} \mathrm{C}$ for three days before recording their dry weights.

\subsection{Chlorophyll Pigments}

A fresh leaf $(0.5 \mathrm{~g})$ was extracted in $10 \mathrm{~mL}$ of acetone $(80 \%)$ and placed all the samples overnight at $4{ }^{\circ} \mathrm{C}$. Then, the extracts were centrifuged at $10,000 \times g$ for $5 \mathrm{~min}$. The supernatant was poured into a quartz cuvette and absorbance was recorded at 480, 645 and $663 \mathrm{~nm}$ on a spectrophotometer. Chlorophyll $a$ and $b$ concentrations were calculated following Arnon [28].

\subsection{Leaf Free Proline Contents}

Fresh leaf $(0.5 \mathrm{~g})$ was homogenized in $10 \mathrm{~mL}$ of $3 \%$ sulfosalicylic acid $(w / v)$ solution. After filtration, $2 \mathrm{~mL}$ of the filtrate was mixed with $2 \mathrm{~mL}$ acid ninhydrin solution and an equal volume of glacial acetic acid was added to it. The mixture was heated at $100{ }^{\circ} \mathrm{C}$ for one $\mathrm{h}$ in a water bath and subsequently cooled in an ice bath. After that, $4 \mathrm{~mL}$ of toluene was added and shaken well the mixture. Two layers were formed in the mixture and the absorbance of the upper layer was noted at $520 \mathrm{~nm}$ using a spectrophotometer. Then, proline contents were calculated following Bates et al. [29].

\subsection{Glycinebetaine (GB)}

Following Grieve and Grattan [30], a fresh leaf $(0.5 \mathrm{~g})$ was ground in $10 \mathrm{~mL}$ distilled water and centrifuged at $10,000 \times \mathrm{g}$ for $10 \mathrm{~min}$. Then, $1.0 \mathrm{~mL}$ of the filtrate was mixed with $1.0 \mathrm{~mL}$ of $2 \mathrm{~N} \mathrm{H}_{2} \mathrm{SO}_{4}$ solution. Then, $0.5 \mathrm{~mL}$ of the mixture was taken in a test tube and potassium tri-iodide $(0.2 \mathrm{~mL})$ was added to it. After it, the mixture was shaken and cooled for $90 \mathrm{~min}$ on ice. Ice-cooled distilled water $(2.8 \mathrm{~mL})$ and 1,2 dichloroethane $(6 \mathrm{~mL})$ were 
added to the reaction mixture. By passing an air stream for $2 \mathrm{~min}$ through the mixture, two layers were formed. Optical density of the upper organic layer was read at $365 \mathrm{~nm}$ using a spectrophotometer.

\subsection{Hydrogen Peroxide $\left(\mathrm{H}_{2} \mathrm{O}_{2}\right)$ Contents}

According to the method of Velikova et al. [31], $0.5 \mathrm{~g}$ fresh leaf was homogenized in $5 \mathrm{~mL}$ of $1.0 \%$ trichloroacetic acid (TCA) in an ice-cooled pestle and mortar. To separate the supernatant, centrifugation was done at $12,000 \times g$ for $15 \mathrm{~min}$. After that, $0.5 \mathrm{~mL}$ of the supernatant was taken with the same volume of potassium-phosphate buffer ( $\mathrm{pH} 7)$ along with $1 \mathrm{~mL}$ of $1 \mathrm{M}$ potassium iodide and mixed well. The optical density (OD) was recorded at $390 \mathrm{~nm}$ to calculate $\mathrm{H}_{2} \mathrm{O}_{2}$ content.

\subsection{Malondialdehyde (MDA)}

Fresh leaf $(0.25 \mathrm{~g})$ was ground in $3 \mathrm{~mL}$ of $5 \%(w / v)$ TCA using a pre-chilled pestle and mortar following Cakmak and Horst [32]. The extract was centrifuged for $15 \mathrm{~min}$ and $0.5 \mathrm{~mL}$ of the supernatant was mixed with $2 \mathrm{~mL} 0.5 \%(w / v)$ thiobarbituric acid prepared in $20 \%$ trichloro-acetic acid. The reaction mixture was heated in a water bath for $50 \mathrm{~min}$ at $95{ }^{\circ} \mathrm{C}$ and cooled. Absorbance of the mixture was recorded at 532 and $600 \mathrm{~nm}$ using a spectrophotometer.

\subsection{Total Phenolics}

Following Julkenen-Titto [33], fresh leaf $(0.1 \mathrm{~g})$ was extracted in $5 \mathrm{~mL}$ of $80 \%$ acetone $(v / v)$. Then, the extract was centrifuged for $10 \mathrm{~min}$ at $10,000 \times g$. Then, $100 \mu \mathrm{L}$ of supernatant, $2 \mathrm{~mL}$ of distilled water and $1 \mathrm{~mL}$ Folin-Ciocalteau's phenol reagent were mixed and shaken well. To that, $5 \mathrm{~mL}$ of sodium carbonate $(20 \%)$ was added and made the final volume as $10 \mathrm{~mL}$ using distilled water. The absorbance was noted at $750 \mathrm{~nm}$ using a spectrophotometer.

\subsection{Ascorbic Acid (AsA)}

The Mukherjee and Choudhuri [34] method was used to determine the ascorbic acid (AsA) contents in fresh leaves of carrot plants. Fresh leaf ( $0.25 \mathrm{~g}$ of each sample) was extracted in $10 \mathrm{~mL}$ solution of $6 \%$ TCA. The filtrate $(4 \mathrm{~mL})$ was taken in test tubes and we added $2 \mathrm{~mL}$ of $2 \%$ dinitrophenyl hydrazine prepared in $\mathrm{H}_{2} \mathrm{SO}_{4}(9 \mathrm{~N})$ solution to each test tube. Then, 1 drop of $10 \%$ thiourea (prepared in $70 \%(v / v)$ ethanol) was added and kept it in a water bath for $15 \mathrm{~min}$ at $100{ }^{\circ} \mathrm{C}$. Then, the filtrate was cooled at room temperature and $5 \mathrm{~mL}$ of $80 \%(v / v) \mathrm{H}_{2} \mathrm{SO}_{4}$ was added to it. Then, the absorbance of the mixture was recorded at $530 \mathrm{~nm}$ using a spectrophotometer.

\subsection{Total Soluble Proteins}

Fresh leaf $(0.5 \mathrm{~g})$ was homogenized in $5 \mathrm{~mL}$ phosphate buffer $(\mathrm{pH} 7)$ in a pre-chilled pestle and mortar according to Bradford [35]. After centrifugation, $100 \mu \mathrm{L}$ of the supernatant was mixed with $5 \mathrm{~mL}$ of the Bradford reagent. The absorbance of the mixture was noted at $595 \mathrm{~nm}$ using a spectrophotometer.

\subsection{Enzymatic Antioxidants}

A fresh leaf $(0.5 \mathrm{~g})$ was homogenized in $5 \mathrm{~mL}$ of $50 \mathrm{mM}$ phosphate buffer (pH 7.8) using a pre-chilled pestle and mortar. Then, the extract was centrifuged for $15 \mathrm{~min}$ at $15,000 \times \mathrm{g}$ at $4{ }^{\circ} \mathrm{C}$. The supernatant was used for the determination of the activities of catalase (CAT) and peroxidase (POD) enzymes following Chance and Maehly [36]. For the determination of the activity of CAT enzyme, leaf extract $(100 \mu \mathrm{L}), 50 \mathrm{mM}$ potassium phosphate buffer (1.9 mL) along with $1 \mathrm{~mL}$ of $5.9 \mathrm{mM} \mathrm{H}_{2} \mathrm{O}_{2}$ were mixed in a cuvette. Changes in absorbance were noted after every $20 \mathrm{~s}$ for $3 \mathrm{~min}$ at $240 \mathrm{~nm}$. For the determination of activity of peroxidase (POD), $100 \mu \mathrm{L}$ of $40 \mathrm{mM} \mathrm{H}_{2} \mathrm{O}_{2}, 100 \mu \mathrm{L}$ of $20 \mathrm{mM}$ guiacol, $50 \mu \mathrm{L}$ of the enzyme extract and $750 \mu \mathrm{L}$ of potassium phosphate buffer were mixed and a change in absorbance 
of the reaction mixture for three minutes was observed at $470 \mathrm{~nm}$. The activities of CAT and POD enzymes were calculated on the basis of total soluble proteins.

\subsection{Statistical Analysis}

A three-way (cultivars, drought and tocopherol) analysis of variance of data of all parameters was employed using the statistical software Statistix 8.1 to assess the level of significance. The least significance difference (LSD) at the 5\% probability level was employed to assess the differences among the treatment means. The heat-map analysis between different variables was constructed using RStudio.

\section{Results}

\subsection{Plant Growth and Biomass}

The effectiveness of varying levels (50 and $100 \mathrm{mg} \mathrm{L}^{-1}$ ) of alpha-tocopherol (Toc) as a seed pre-treatment in stress tolerance (water-deficit) of carrot plants was investigated in the present study. Two cultivars of carrot, DC4 and DC90, were subjected to $100 \%$ FC (control) and 50\% FC (water stress). Data indicated that all morphological attributes including shoot fresh and dry weights $(p \leq 0.001)$, root fresh and dry weights $(p \leq 0.05)$, as well as shoot and root lengths ( $p \leq 0.01$ and 0.05$)$, decreased significantly under water deficit conditions. Seed priming with Toc considerably $(p \leq 0.001 ; 0.01)$ improved all the growth attributes of carrot plants subjected to both water regimes. Of both levels of Toc, $100 \mathrm{mg} \mathrm{L}^{-1}$ was found to be more effective in enhancing the growth attributes than the other Toc level under water shortage conditions (Figure 1). Of both carrot cultivars, cv. DC4 had better performance in terms of shoot and root fresh weights, as well as root length under both water regimes. The response of both carrot cultivars to water stress and exogenously applied Toc was similar for other growth attributes.

\subsection{Photosynthetic Pigment}

Drought stress significantly ( $p \leq 0.001$ ) suppressed chlorophyll $a, b$ and total content of both carrot cultivars (Figure 2). Moreover, exogenously applied alpha-tocopherol as a pre-sowing seed treatment significantly $(p \leq 0.01)$ improved the chlorophyll content of both cultivars under water limited conditions. It was noticed that tocopherol applied as $100 \mathrm{mg} / \mathrm{L}$ was more effective than the other level in regulating the concentrations of the photosynthetic pigments. However, no significant change was observed in chlorophyll $\mathrm{a} / \mathrm{b}$ ratio of both carrot cultivars subjected to water stress as well as an exogenous supply of Toc. The trend of decrease in chlorophyll pigments was consistent in both carrot cultivars under varying water stress and Toc treatments (Figure 2).

\subsection{Proline Content}

No significant change was observed in proline content of both carrot cultivars under the water limited regimes (Figure 2). The seed treatment with alpha-tocopherol enhanced $(p \leq 0.01)$ the accumulation of proline content under both water regimes. Of both Toc levels, maximum accumulation in proline content was observed at $100 \mathrm{mg} \mathrm{L}^{-1}$ under varying water regimes. The response of both carrot cultivars was almost similar under water stress and Toc treatments.

\subsection{Glycinebetaine Content}

A prominent $(p \leq 0.01)$ increase in glycinebetaine (GB) content was observed in water-stressed carrot plants. The pre-sowing seed treatment with Toc triggered $(p \leq 0.01)$ the accumulation of GB content under varying water supply conditions. Of both Toc levels, $100 \mathrm{mg} \mathrm{L}^{-1}$ was more effective in causing the accumulation of the GB content under varying water regimes. No significant difference in GB accumulation was noticed in both carrot cultivars (Figure 2). 


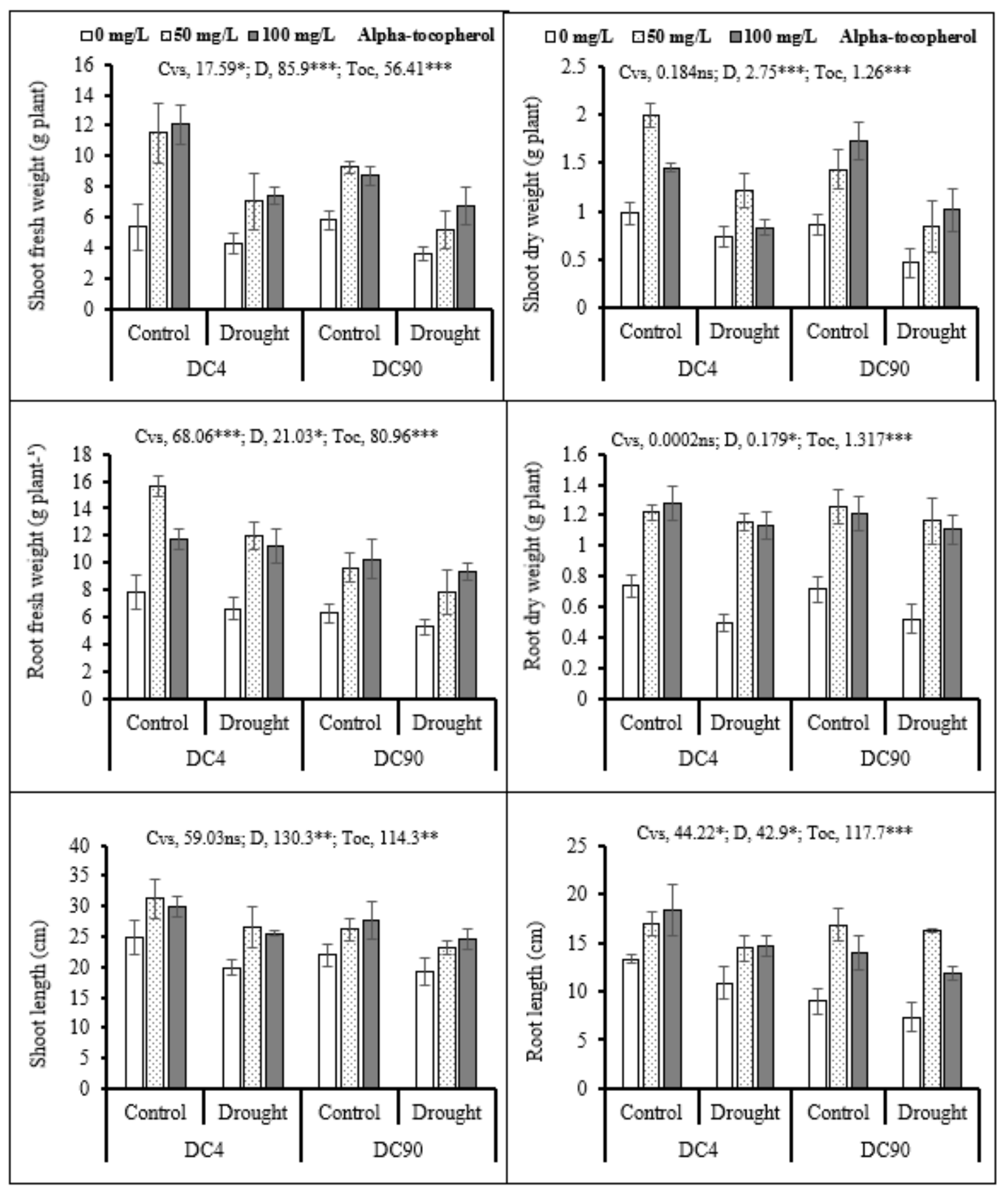

Figure 1. Effect of different levels of alpha-tocopherol on shoot fresh weight, shoot dry weight, root fresh weight, root dry weight, shoot length and root length of 51-day-old carrot cultivar grown under control (normal watering) and drought (50\% field capacity) stressed environments. Bars sharing different letter(s) for each parameter are significantly different from each other according to Duncan's multiple range test $(p<0.05)$. All the data represented are the average of three replications $(n=3)$. Error bars represent standard deviation (SD) of three replicates. ns, non-significant, ${ }^{*}, * *$ and ${ }^{* * *}$; significant at 0.05 , 0.01 and 0.001 levels. 


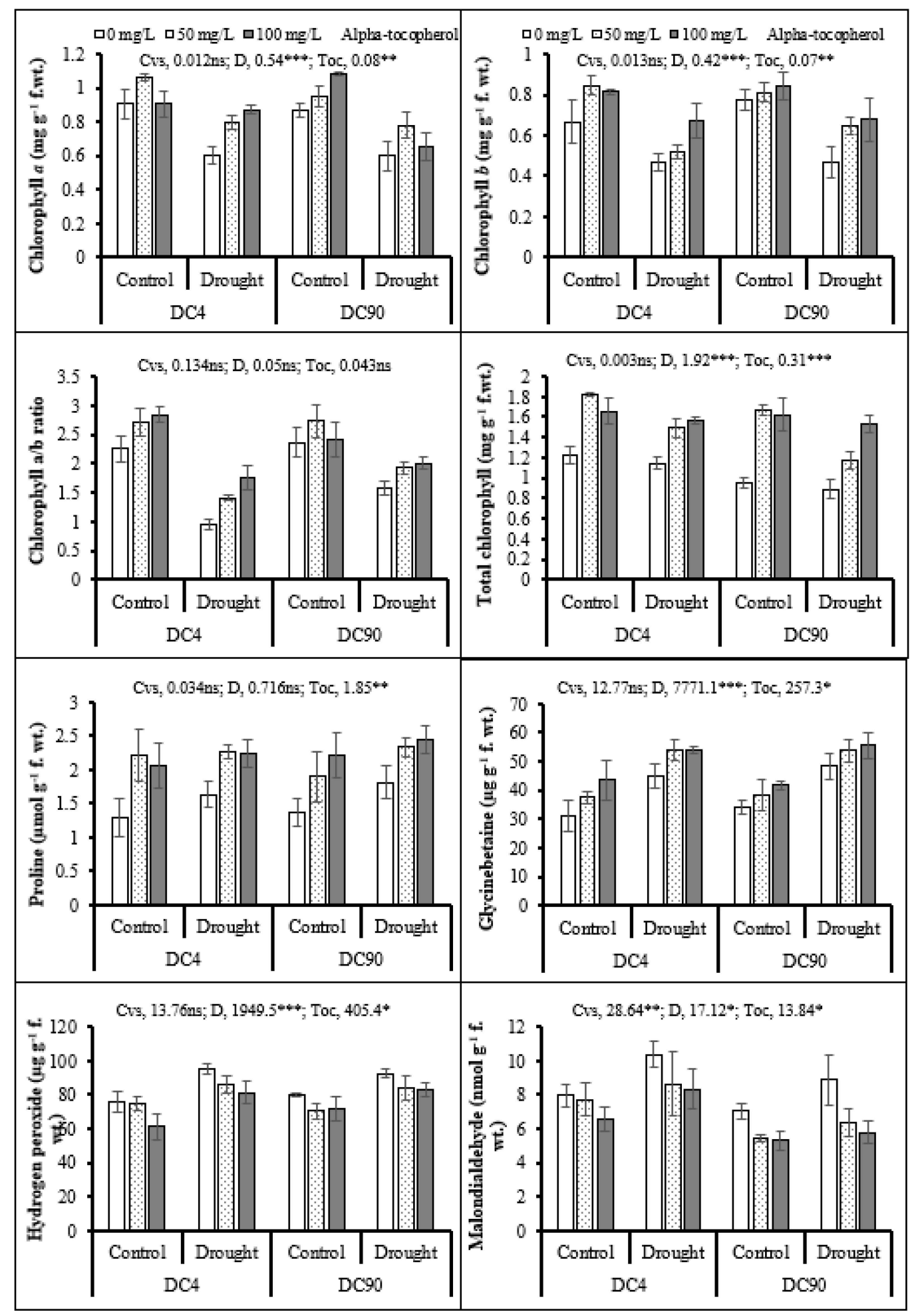

Figure 2. Effect of different levels of alpha-tocopherol on chlorophyll ( $a, b, a / b$ ratio, total) content, proline, glycinebetaine (GB), hydrogen peroxide and malondialdehyde content of 51-day-old carrot cultivar grown under control (normal watering) and drought (50\% field capacity) stressed environments. Bars sharing different letter(s) for each parameter are significantly different from each other according to Duncan's multiple range test $(p<0.05)$. All the data represented are the average of three replications $(n=3)$. Error bars represent standard deviation (SD) of three replicates. ns, non-significant, ${ }^{* * *}$ and ${ }^{* * *}$; significant at $0.05,0.01$ and 0.001 levels. 


\subsection{Oxidative Stress Indicators}

Under water stress conditions, hydrogen peroxide $\left(\mathrm{H}_{2} \mathrm{O}_{2}\right)$ and malondialdehyde (MDA) were found to accumulate considerably ( $p \leq 0.001$ and 0.05 , respectively) as compared to that in the control plants of both carrot cultivars. Exogenous application of Toc was effective $(p \leq 0.05)$ in minimizing the $\mathrm{H}_{2} \mathrm{O}_{2}$ and MDA accumulation in drought-stressed carrot plants (Figure 2). The response of both carrot cultivars was consistent in both these attributes.

\subsection{Non-Enzymatic Antioxidant}

Ascorbic acid (AsA) and total phenolic concentrations increased significantly $(p \leq 0.001)$ in both carrot cultivars under water scarce conditions (Figure 3). Both levels of alphatocopherol significantly ( $p \leq 0.01,0.001$, respectively) improved the AsA and total phenolic content in both carrot cultivars under water stress as well as non-stress conditions. Of both Toc levels, $100 \mathrm{mg} \mathrm{L}^{-1}$ was the most effective in enhancing the AsA and total phenolic content in the water-stressed plants of both carrot cultivars. However, no difference was observed in the two carrot cultivars in AsA and total phenolics under varying water regimes.

\subsection{Protein Content}

A significant decrease $(p \leq 0.001)$ was observed in total soluble proteins (TSP) of both carrot cultivars under drought stress (Figure 3). However, application of alphatocopherol improved the TSP in both carrot cultivars under varying water regimes. Overall, $100 \mathrm{mg} \mathrm{L}^{-1}$ of alpha-tocopherol was most effective in regulating the levels of TSP in both carrot cultivars. A non-significant difference was observed in the two carrot cultivars in terms of TSP.

\subsection{Enzymatic Antioxidant}

The activities of catalase (CAT) and peroxidase (POD) enzymes enhanced significantly $(p \leq 0.001)$ in both carrot cultivars under water deficit conditions (Figure 3). Exogenous application of alpha-tocopherol, particularly $100 \mathrm{mg} \mathrm{L}^{-1}$, tended to upregulate the activities of both enzymes under water deficit conditions. No significant change in both carrot cultivars was observed in terms of the activities of CAT and POD enzymes.

\subsection{Relationship}

A heat-map correlation analysis was constructed to quantify the relation between different parameters studied in this experiment. The graphical representation of DC4 variety is presented in Figure 4. DC4 variety showed more resistance in the droughtstressed environment, so we constructed only one heat-map analysis using DC4 variety. The results from the constructed heat-map analysis show that plants grown in control conditions under the application of $100 \mathrm{mg} \mathrm{L}^{-1}$ of alpha-tocopherol were highly significant with their growth parameters, while the rest of the parameters in controlled and droughtstressed environments showed that different growth and physiological parameters were decreasing or non-significant under increasing levels of alpha-tocopherol. Hence, this relationship is showing a close connection between growth of DC4 under drought and controlled environments, with the application of alpha-tocopherol. 


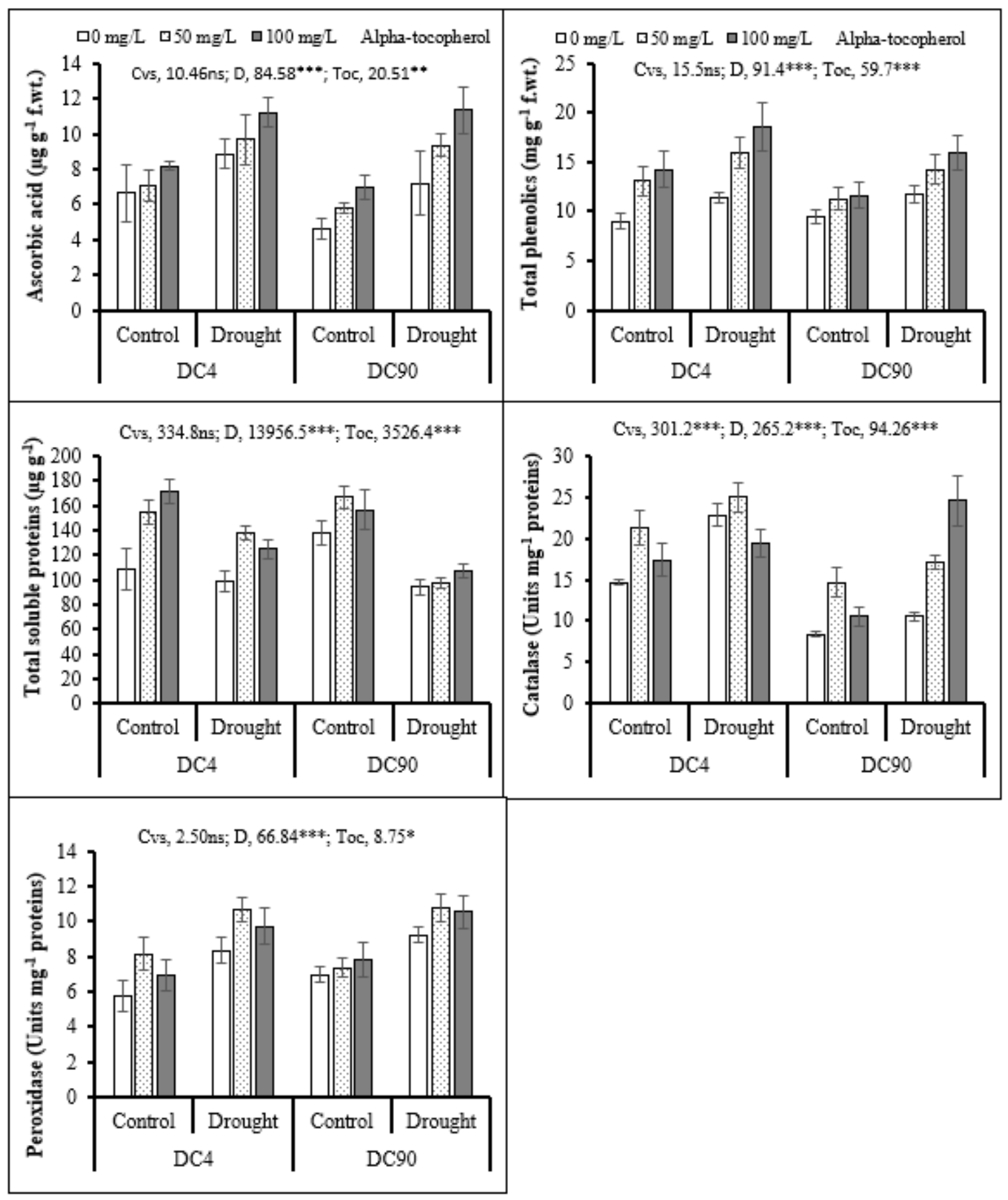

Figure 3. Effect of different levels of alpha-tocopherol on ascorbic acid, total phenolics, total soluble proteins and activities of catalase and peroxidase enzymes of 51-day-old carrot cultivar grown under control (normal watering) and drought (50\% field capacity) stressed environments. Bars sharing different letter(s) for each parameter are significantly different from each other according to Duncan's multiple range test $(p<0.05)$. All the data represented are the average of three replications $(n=3)$. Error bars represent standard deviation (SD) of three replicates. ns, non-significant, ${ }^{*}, * *$ and ${ }^{* * *}$; significant at 0.05 , 0.01 and 0.001 levels. 


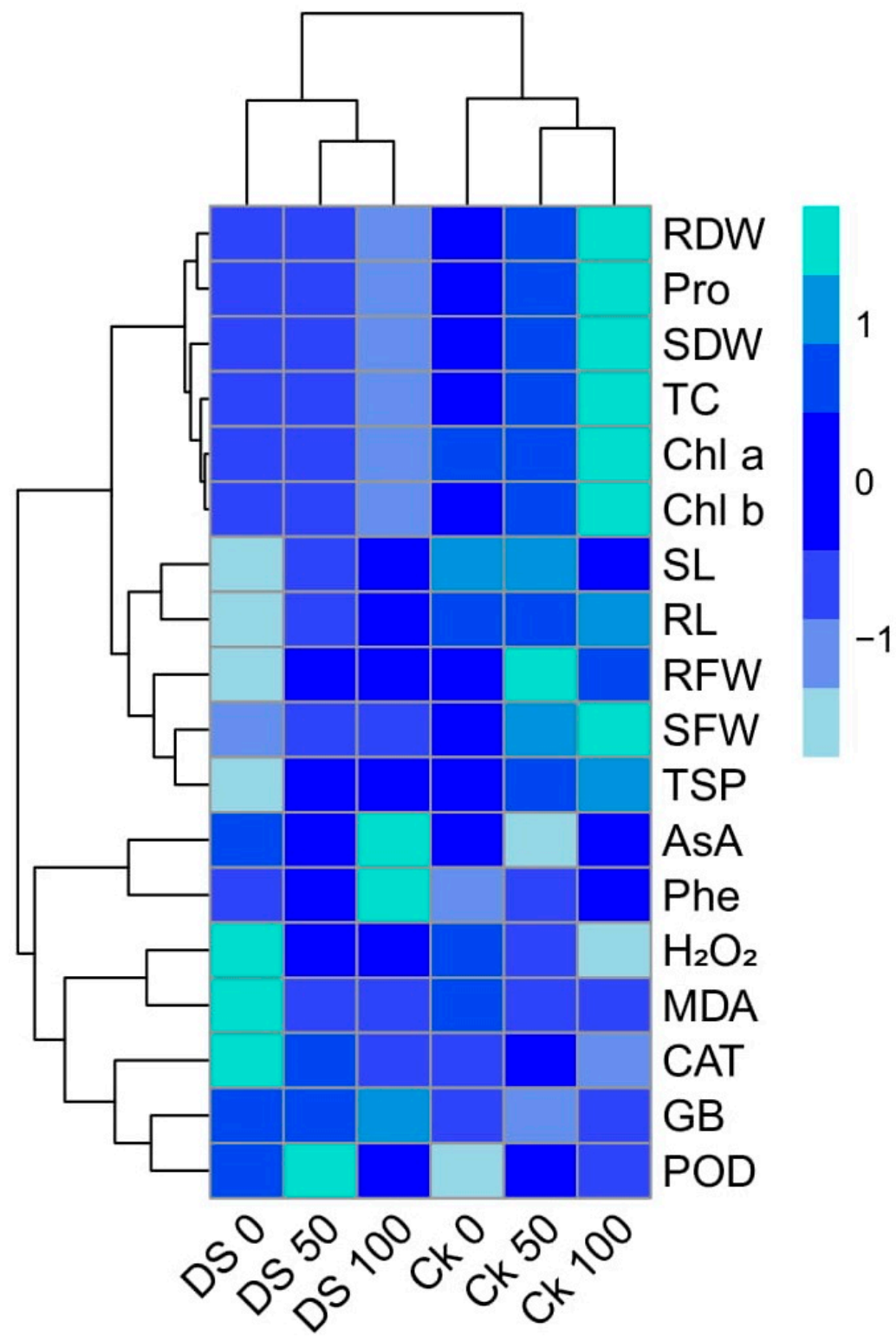

Figure 4. Heat-map analysis between various growth and physiological attributes in carrot grown in control and drought-stressed environment. Different treatments in the base of the figure are as follows-DS 0 (Drought-stressed environment with $0 \mathrm{mg} \mathrm{L}^{-1}$ of alpha-tocopherol), DS 50 (Droughtstressed environment with $50 \mathrm{mg} \mathrm{L}^{-1}$ of alpha-tocopherol), DS 100 (Drought-stressed environment with $100 \mathrm{mg} \mathrm{L}^{-1}$ of alpha-tocopherol), Ck 0 (Sufficient watered supply with $0 \mathrm{mg} \mathrm{L}^{-1}$ of alphatocopherol), Ck 50 (Sufficient watered supply with $50 \mathrm{mg} \mathrm{L}^{-1}$ of alpha-tocopherol) and Ck 100 (Sufficient watered supply with $100 \mathrm{mg} \mathrm{L}^{-1}$ of alpha-tocopherol). Different abbreviations used in the figure are as follows-RDW (root dry weight), Pro (proline content), SDW (shoot dry weight), TC (total chlorophyll content), Chl a (chlorophyll a content), Chl b (chlorophyll b contents), SL (shoot length), RL (root length), RFW (root fresh weight), SFW (shoot fresh weight), TSP (total soluble protein), AsA (ascorbic acid content), Phe (phenolic content), $\mathrm{H}_{2} \mathrm{O}_{2}$ (hydrogen peroxide initiation), MDA (malondialdehyde content), CAT (catalase activity), GB (glycinebetaine) and POD (peroxide activity).

\section{Discussion}

Exogenously applied plant growth regulators are reported to be very effective in improving stress tolerance in plants $[18,37]$. Of different growth regulators, the application of lipophilic antioxidative compounds including tocopherols (Toc) is very effective in 
increasing plant growth and yield on stressed environments particularly by ameliorating the stress-induced adversaries [20]. Exogenously applied alpha-tocopherol was reported to be effective in improving the plant growth in different plants, e.g., Vicia faba [38], wheat [39] and Vigna radiata [40] under drought stress conditions. Water stress is one of the largest emerging abiotic stresses adversely affecting places all over the world due to anthropogenic as well as rapid climatic changes [41]. Deficiency of water perturbs many plant processes from seed germination to seed formation [42]. Generally, reduction in plant growth and yield production was associated with water stress-induced osmotic stress, nutritional and hormonal imbalance, over-production of ROS as well as disturbance in proteins synthesis [1,8]. In the present study, both carrot cultivars (DC4 and DC90) showed a significant decrease in shoot and root lengths as well as overall plant growth. However, seed treatment with Toc ( 50 and $100 \mathrm{mg} \mathrm{L}^{-1}$ ) improved the shoot and root fresh and dry weights as well as lengths (shoot and root) of carrot plants. This Toc-induced improvement in plant growth has been already reported to be associated with different metabolic processes such as better water status, uptake of essential nutrients, up-regulation of the oxidative defense system, stomatal functioning, improved rate of photosynthesis, synthesis of chlorophyll and accumulation of osmoprotectants under stress conditions $[3,6,41]$.

Chlorophyll content declined significantly in both carrot cultivars under water stress regimes. However, the application of alpha-tocopherol significantly increased the chlorophyll content in both carrot cultivars under water stress. The decrease in pigments in response to drought stress is a common phenomenon reported in various crops like carrot [10], mung bean [40], and canola [3]. However, supply of Toc has been reported to mitigate the stress-induced adversaries in plants. For example, while working with mung bean, Sadiq et al. [40] applied Toc at the rate of $300 \mathrm{mg} \mathrm{L}^{-1}$ as a foliar spray and found a significant improvement in chlorophyll $a$ and $b$ content under water-deficit conditions. In fact, alpha-tocopherol is believed to play an effective role in the xanthophyll cycle taking place in chloroplasts particularly to preserve membrane lipids and protect PSII from photo-inactivation, thereby keeping the chlorophyll contents intact [22].

A significant increase in GB and proline content was observed due to pre-sowing seed treatment with Toc under limited water supply. Of both Toc levels, $100 \mathrm{mg} \mathrm{L}^{-1}$ was more effective in causing the accumulation of proline and GB content under varying water regimes. Glycinebetaine and proline are known to act as compatible organic solutes for osmotic adjustment and as ROS scavengers for improving plant water status $[18,40]$. For instance, the accumulation of GB and proline is a common response of plants exposed to stress conditions as a defense mechanism to alleviate the stress adversaries $[43,44]$. In this study, water stress remained ineffective to alter the levels of proline, whereas it caused enhanced accumulation of GB; however, exogenous application of Toc increased the accumulation of both GB and proline in both carrot cultivars. Similar results regarding Toc-induced proline accumulation were reported by Orabi and Abdelhamid [45] in the leaves of faba bean plants under salt stress, and by Sadiq et al. [40] in pods of mung bean under drought stress.

High accumulation of ROS beyond the tolerance level in different plant species is one of the selection criteria for selecting sensitive cultivars of different crops under water stress conditions [46]. In the current study, accumulation of $\mathrm{H}_{2} \mathrm{O}_{2}$ and MDA (both indicators of oxidative stress) increased considerably in both carrot cultivars under water-limited regimes. However, exogenously applied Toc effectively minimized the accumulation of $\mathrm{H}_{2} \mathrm{O}_{2}$ and MDA content in water-stressed carrot plants (Figure 2). The response of both carrot cultivars was similar to drought stress with respect to ROS species. In response to high ROS production under water deficiency, triggering of antioxidants (enzymatic and non-enzymatic) is considered as one of the promising strategies of water stress-tolerant plants [4]. In the present study, we found that non-enzymatic antioxidants (ascorbic acid and total phenolic contents) increased significantly under drought stress conditions in both carrot cultivars. Both AsA and total phenolics are well-known to detoxify the ROS produced under stress conditions [47]. Moreover, in the present study the activities of enzy- 
matic antioxidant (POD and CAT) increased significantly in both carrot cultivars (DC4 and DC90) under water scarce conditions. Moreover, exogenously applied alpha-tocopherol improved the activities of these enzymes under water-deficit conditions. Analogous to the results of the current study, Sadiq et al. [40] observed that exogenously applied Toc (200 and $300 \mathrm{mg} \mathrm{L}^{-1}$ ) considerably enhanced the activities of SOD, POD and CAT antioxidant enzymes in mung bean pods under water deficit conditions. It is well evident that improvement in antioxidative defense system suppresses the oxidative stress specifically by increasing the activities of peroxidase and catalase enzymes $[48,49]$. It is important to note that the exogenously applied plant growth regulators altered enzymatic and non-enzymatic machinery that may have prevented the cell membrane from the damages induced by over-production of ROS [50,51].

\section{Conclusions}

In general, water stress considerably reduced the plant growth, chlorophyll pigments and total soluble proteins, while it increased the accumulation of $\mathrm{GB}, \mathrm{H}_{2} \mathrm{O}_{2}, \mathrm{MDA}$, AsA, total phenolics and the activities of enzymatic antioxidant (CAT and POD) enzymes. Seed soaking treatment with Toc was effective in reducing the accumulation of $\mathrm{H}_{2} \mathrm{O}_{2}$ and MDA content, while it improved plant growth, chlorophyll, proline, GB, AsA, total phenolics, TSP content and the activities of CAT and POD enzymes. Cultivar DC4 was better in plant growth, while the response of the two cultivars was similar in all other attributes to water stress. Overall, seed treatment with $100 \mathrm{mg} \mathrm{L}^{-1}$ Toc was very effective in enhancing plant growth, accumulation of osmoprotectants and upregulation of the oxidative defense system of carrot plants under water-deficit conditions.

Author Contributions: Conceptualization, M.A.; Data curation, A.H. and S.A. (Shakeel Ahmed); Formal analysis, A.H.; Investigation, N.A.A. and M.H.S.; Methodology, N.A.A. and M.A.; Resources, M.N.A.; Software, A.A.A. and M.N.A.; Validation, M.H.S., M.A. and S.A. (Shakeel Ahmed); Visualization, S.A. (Shakeel Ahmed), S.A. (Shafaqat Ali) and M.N.A.; Writing-original draft, A.H., N.A.A., M.H.S., S.A. (Shafaqat Ali) and A.A.A.; Writing-review and editing, S.A. (Shafaqat Ali) and A.A.A. All authors have read and agreed to the published version of the manuscript.

Funding: The authors highly acknowledge the Higher Education Commission (HEC), Islamabad, Pakistan for its support. The authors would like to extend their sincere appreciation to the Researchers Supporting Project Number (RSP-2020/236), King Saud University, Riyadh, Saudi Arabia.

Acknowledgments: The authors highly acknowledge the Government College University Faisalabad, Pakistan for its support. The authors would like to extend their sincere appreciation to the Researchers Supporting Project Number (RSP-2020/236), King Saud University, Riyadh, Saudi Arabia.

Conflicts of Interest: The author declares no conflict of interest.

\section{References}

1. Yaseen, R.; Aziz, O.; Saleem, M.H.; Riaz, M.; Zafar-ul-Hye, M.; Rehman, M.; Ali, S.; Rizwan, M.; Nasser Alyemeni, M.; El-Serehy, H.A. Ameliorating the drought stress for wheat growth through application of ACC-Deaminase containing rhizobacteria along with biogas slurry. Sustainability 2020, 12, 6022. [CrossRef]

2. Alam, H.; Khattak, J.Z.K.; Ksiksi, T.S.; Saleem, M.H.; Fahad, S.; Sohail, H.; Ali, Q.; Zamin, M.; El-Esawi, M.A.; Saud, S. Negative impact of long-term exposure of salinity and drought stress on native Tetraena mandavillei L. Physiol. Plant. 2020. [CrossRef] [PubMed]

3. Akram, N.A.; Iqbal, M.; Muhammad, A.; Ashraf, M.; Al-Qurainy, F.; Shafiq, S. Aminolevulinic acid and nitric oxide regulate oxidative defense and secondary metabolisms in canola (Brassica napus L.) under drought stress. Protoplasma 2018, 255, 163-174. [CrossRef] [PubMed]

4. Hasanuzzaman, M.; Nahar, K.; Anee, T.; Khan, M.; Fujita, M. Silicon-mediated regulation of antioxidant defense and glyoxalase systems confers drought stress tolerance in Brassica napus L. S. Afr. J. Bot. 2018, 115, 50-57. [CrossRef]

5. Abid, M.; Hakeem, A.; Shao, Y.; Liu, Y.; Zahoor, R.; Fan, Y.; Suyu, J.; Ata-Ul-Karim, S.T.; Tian, Z.; Jiang, D. Seed osmopriming invokes stress memory against post-germinative drought stress in wheat (Triticum aestivum L.). Environ. Exp. Bot. 2018, 145, 12-20. [CrossRef] 
6. Kosar, F.; Akram, N.; Ashraf, M. Exogenously-applied 5-aminolevulinic acid modulates some key physiological characteristics and antioxidative defense system in spring wheat (Triticum aestivum L.) seedlings under water stress. S. Afr. J. Bot. 2015, 96, 71-77. [CrossRef]

7. Adrees, M.; Khan, Z.S.; Ali, S.; Hafeez, M.; Khalid, S.; ur Rehman, M.Z.; Hussain, A.; Hussain, K.; Chatha, S.A.S.; Rizwan, M. Simultaneous mitigation of cadmium and drought stress in wheat by soil application of iron nanoparticles. Chemosphere 2020, 238, 124681. [CrossRef]

8. Fahad, S.; Bajwa, A.A.; Nazir, U.; Anjum, S.A.; Farooq, A.; Zohaib, A.; Sadia, S.; Nasim, W.; Adkins, S.; Saud, S. Crop production under drought and heat stress: Plant responses and management options. Front. Plant Sci. 2017, 8, 1147. [CrossRef]

9. Sadiq, M.; Akram, N.A.; Javed, M.T. Alpha-tocopherol alters endogenous oxidative defense system in mung bean plants under water-deficit conditions. Pak. J. Bot 2016, 48, 2177-2182.

10. Razzaq, M.; Akram, N.A.; Ashraf, M.; Naz, H.; Al-Qurainy, F. Interactive effect of drought and nitrogen on growth, some key physiological attributes and oxidative defense system in carrot (Daucus carota L.) plants. Sci. Hortic. 2017, 225, 373-379. [CrossRef]

11. Kosar, F.; Akram, N.A.; Ashraf, M.; Ahmad, A.; Alyemeni, M.N.; Ahmad, P. Impact of exogenously applied trehalose on leaf biochemistry, achene yield and oil composition of sunflower under drought stress. Physiol. Plant. 2020. [CrossRef]

12. Farooq, A.; Bukhari, S.A.; Akram, N.A.; Ashraf, M.; Wijaya, L.; Alyemeni, M.N.; Ahmad, P. Exogenously Applied Ascorbic Acid-Mediated Changes in Osmoprotection and Oxidative Defense System Enhanced Water Stress Tolerance in Different Cultivars of Safflower (Carthamus tinctorious L.). Plants 2020, 9, 104. [CrossRef]

13. Hussain, M.I.; Lyra, D.-A.; Farooq, M.; Nikoloudakis, N.; Khalid, N. Salt and drought stresses in safflower: A review. Agron. Sustain. Dev. 2016, 36, 4. [CrossRef]

14. Saleem, M.; Ali, S.; Rehman, M.; Rana, M.; Rizwan, M.; Kamran, M.; Imran, M.; Riaz, M.; Hussein, M.; Elkelish, A.; et al. Influence of phosphorus on copper phytoextraction via modulating cellular organelles in two jute (Corchorus capsularis L.) varieties grown in a copper mining soil of Hubei Province, China. Chemosphere 2020. [CrossRef]

15. Saleem, M.H.; Kamran, M.; Zhou, Y.; Parveen, A.; Rehman, M.; Ahmar, S.; Malik, Z.; Mustafa, A.; Anjum, R.M.A.; Wang, B. Appraising growth, oxidative stress and copper phytoextraction potential of flax (Linum usitatissimum L.) grown in soil differentially spiked with copper. J. Environ. Manag. 2020, 257, 109994. [CrossRef]

16. Noreen, S.; Fatima, K.; Athar, H.; Ahmad, S.; Hussain, K. Enhancement of physio-biochemical parameters of wheat through exogenous application of salicylic acid under drought stress. J. Anim. Plant Sci. 2017, 27, 153-163.

17. Mohamed, I.A.; Shalby, N.; MA El-Badri, A.; Saleem, M.H.; Khan, M.N.; Nawaz, M.A.; Qin, M.; Agami, R.A.; Kuai, J.; Wang, B. Stomata and Xylem Vessels Traits Improved by Melatonin Application Contribute to Enhancing Salt Tolerance and Fatty Acid Composition of Brassica napus L. Plants. Agronomy 2020, 10, 1186. [CrossRef]

18. Nazar, Z.; Akram, N.A.; Saleem, M.H.; Ashraf, M.; Ahmed, S.; Ali, S.; Abdullah Alsahli, A.; Alyemeni, M.N. GlycinebetaineInduced Alteration in Gaseous Exchange Capacity and Osmoprotective Phenomena in Safflower (Carthamus tinctorius L.) under Water Deficit Conditions. Sustainability 2020, 12, 10649. [CrossRef]

19. Semida, W.M.; Abd El-Mageed, T.A.; Howladar, S.M.; Rady, M.M. Foliar-applied alpha-tocopherol enhances salt-tolerance in onion plants by improving antioxidant defence system. Aust. J. Crop. Sci. 2016, 10, 1030. [CrossRef]

20. Sadiq, M.; Akram, N.A.; Ashraf, M.; Al-Qurainy, F.; Ahmad, P. Alpha-tocopherol-induced regulation of growth and metabolism in plants under non-stress and stress conditions. J. Plant Growth Regul. 2019, 38, 1325-1340. [CrossRef]

21. Srinivasan, A.; Vijayakumar, S.; Raman, K.; Srivastava, S. Rational metabolic engineering for enhanced alpha-tocopherol production in Helianthus annuus cell culture. Biochem. Eng. J. 2019, 151, 107256. [CrossRef]

22. Sereflioglu, S.; Dinler, B.S.; Tasci, E. Alpha-tocopherol-dependent salt tolerance is more related with auxin synthesis rather than enhancement antioxidant defense in soybean roots. Acta Biol. Hung. 2017, 68, 115-125. [CrossRef]

23. Sadak, M.S.; Abdelhamid, M.T. Influence of amino acids mixture application on some biochemical aspects, antioxidant enzymes and endogenous polyamines of Vicia faba plant grown under seawater salinity stress. Gesunde Pflanz. 2015, 67, 119-129. [CrossRef]

24. Kumar, S.; Singh, R.; Nayyar, H. $\alpha$-Tocopherol application modulates the response of wheat (Triticum aestivum L.) seedlings to elevated temperatures by mitigation of stress injury and enhancement of antioxidants. J. Plant Growth Regul. 2013, 32, 307-314. [CrossRef]

25. Sadiq, M.; Akram, N.A.; Ashraf, M. Impact of exogenously applied tocopherol on some key physio-biochemical and yield attributes in mungbean [Vigna radiata (L.) Wilczek] under limited irrigation regimes. Acta Physiol. Plant. 2018, 40, 131. [CrossRef]

26. Que, F.; Hou, X.-L.; Wang, G.-L.; Xu, Z.-S.; Tan, G.-F.; Li, T.; Wang, Y.-H.; Khadr, A.; Xiong, A.-S. Advances in research on the carrot, an important root vegetable in the Apiaceae family. Hortic. Res. 2019, 6, 1-15. [CrossRef]

27. Sharma, K.D.; Karki, S.; Thakur, N.S.; Attri, S. Chemical composition, functional properties and processing of carrot-A Review. J. Food Sci. Technol. 2012, 49, 22-32. [CrossRef]

28. Arnon, D.I. Copper enzymes in isolated chloroplasts. Polyphenoloxidase in Beta vulgaris. Plant Physiol. 1949, 24, 1. [CrossRef] [PubMed]

29. Bates, L.S.; Waldren, R.P.; Teare, I. Rapid determination of free proline for water-stress studies. Plant. Soil 1973, 39, 205-207. [CrossRef]

30. Grieve, C.; Grattan, S. Rapid assay for determination of water soluble quaternary ammonium compounds. Plant Soil 1983, 70, 303-307. [CrossRef] 
31. Velikova, V.; Yordanov, I.; Edreva, A. Oxidative stress and some antioxidant systems in acid rain-treated bean plants: Protective role of exogenous polyamines. Plant Sci. 2000, 151, 59-66. [CrossRef]

32. Cakmak, I.; Marschner, H. Magnesium deficiency and high light intensity enhance activities of superoxide dismutase, ascorbate peroxidase, and glutathione reductase in bean leaves. Plant Physiol. 1992, 98, 1222-1227. [CrossRef] [PubMed]

33. Julkunen-Tiitto, R. Phenolic constituents in the leaves of northern willows: Methods for the analysis of certain phenolics. J. Agric. Food Chem. 1985, 33, 213-217. [CrossRef]

34. Mukherjee, S.; Choudhuri, M. Implications of water stress-induced changes in the levels of endogenous ascorbic acid and hydrogen peroxide in Vigna seedlings. Physiol. Plant. 1983, 58, 166-170. [CrossRef]

35. Bradford, M.M. A rapid and sensitive method for the quantitation of microgram quantities of protein utilizing the principle of protein-dye binding. Anal. Biochem. 1976, 72, 248-254. [CrossRef]

36. Chance, B.; Maehly, A.C. Assay of catalases and peroxidases. Methods Biochem. Anal. 1955, 1, 357-424.

37. Saleem, M.H.; Ali, S.; Kamran, M.; Iqbal, N.; Azeem, M.; Tariq Javed, M.; Ali, Q.; Zulqurnain Haider, M.; Irshad, S.; Rizwan, M. Ethylenediaminetetraacetic Acid (EDTA) Mitigates the Toxic Effect of Excessive Copper Concentrations on Growth, Gaseous Exchange and Chloroplast Ultrastructure of Corchorus capsularis L. and Improves Copper Accumulation Capabilities. Plants 2020, 9, 756. [CrossRef] [PubMed]

38. Semida, W.; Taha, R.; Abdelhamid, M.; Rady, M. Foliar-applied $\alpha$-tocopherol enhances salt-tolerance in Vicia faba L. plants grown under saline conditions. S. Afr. J. Bot. 2014, 95, 24-31. [CrossRef]

39. Ali, Q.; Ali, S.; Iqbal, N.; Javed, M.T.; Rizwan, M.; Khaliq, R.; Shahid, S.; Perveen, R.; Alamri, S.A.; Alyemeni, M.N. Alphatocopherol fertigation confers growth physio-biochemical and qualitative yield enhancement in field grown water deficit wheat (Triticum aestivum L.). Sci. Rep. 2019, 9, 1-15. [CrossRef] [PubMed]

40. Sadiq, M.; Akram, N.A.; Ashraf, M. Foliar applications of alpha-tocopherol improves the composition of fresh pods of Vigna radiata subjected to water deficiency. Turk. J. Bot. 2017, 41, 244-252. [CrossRef]

41. Pareek, A.; Dhankher, O.P.; Foyer, C.H. Mitigating the Impact of Climate Change on Plant Productivity and Ecosystem Sustainability; Oxford University Press: Oxford, UK, 2020.

42. Ahmad, Z.; Waraich, E.A.; Ahmad, R.; Shahbaz, M. Modulation in water relations, chlorophyll contents and antioxidants activity of maize by foliar phosphorus application under drought stress. Pak. J. Bot. 2017, 49, 11-19.

43. Munns, R.; Tester, M. Mechanisms of salinity tolerance. Annu. Rev. Plant Biol. 2008, 59, 651-681. [CrossRef] [PubMed]

44. Saleem, M.H.; Fahad, S.; Khan, S.U.; Ahmar, S.; Khan, M.H.U.; Rehman, M.; Maqbool, Z.; Liu, L. Morpho-physiological traits, gaseous exchange attributes, and phytoremediation potential of jute (Corchorus capsularis L.) grown in different concentrations of copper-contaminated soil. Ecotoxicol. Environ. Saf. 2020, 189, 109915. [CrossRef] [PubMed]

45. Orabi, S.A.; Abdelhamid, M.T. Protective role of $\alpha$-tocopherol on two Vicia faba cultivars against seawater-induced lipid peroxidation by enhancing capacity of anti-oxidative system. J. Saudi Soc. Agric. Sci. 2016, 15, 145-154. [CrossRef]

46. Saleem, M.H.; Ali, S.; Seleiman, M.F.; Rizwan, M.; Rehman, M.; Akram, N.A.; Liu, L.; Alotaibi, M.; Al-Ashkar, I.; Mubushar, M. Assessing the Correlations between Different Traits in Copper-Sensitive and Copper-Resistant Varieties of Jute (Corchorus capsularis L.). Plants 2019, 8, 545. [CrossRef]

47. Javed, M.T.; Saleem, M.H.; Aslam, S.; Rehman, M.; Iqbal, N.; Begum, R.; Ali, S.; Alsahli, A.A.; Alyemeni, M.N.; Wijaya, L. Elucidating silicon-mediated distinct morpho-physio-biochemical attributes and organic acid exudation patterns of cadmium stressed Ajwain (Trachyspermum ammi L.). Plant Physiol. Biochem. 2020, 157, 23-37. [CrossRef]

48. Rehman, M.; Fahad, S.; Saleem, M.H.; Hafeez, M.; Rahman, M.H.; Liu, F.; Deng, G. Red light optimized physiological traits and enhanced the growth of ramie (Boehmeria nivea L.). Photosynthetica 2020, 58, 922-931. [CrossRef]

49. Saleem, M.H.; Rehman, M.; Fahad, S.; Tung, S.A.; Iqbal, N.; Hassan, A.; Ayub, A.; Wahid, M.A.; Shaukat, S.; Liu, L.; et al. Leaf gas exchange, oxidative stress, and physiological attributes of rapeseed (Brassica napus L.) grown under different light-emitting diodes. Photosynthetica 2020, 58, 836-845. [CrossRef]

50. Parveen, A.; Saleem, M.H.; Kamran, M.; Haider, M.Z.; Chen, J.-T.; Malik, Z.; Rana, M.S.; Hassan, A.; Hur, G.; Javed, M.T. Effect of Citric Acid on Growth, Ecophysiology, Chloroplast Ultrastructure, and Phytoremediation Potential of Jute (Corchorus capsularis L.) Seedlings Exposed to Copper Stress. Biomolecules 2020, 10, 592. [CrossRef]

51. Afzal, J.; Saleem, M.H.; Batool, F.; Elyamine, A.M.; Rana, M.S.; Shaheen, A.; El-Esawi, M.A.; Tariq Javed, M.; Ali, Q.; Arslan Ashraf, M.; et al. Role of Ferrous Sulfate (FeSO4) in Resistance to Cadmium Stress in Two Rice (Oryza sativa L.) Genotypes. Biomolecules 2020, 10, 1693. [CrossRef] 